\title{
Patterns of urinary albumin and lgM associate with markers of vascular ageing in young to middle-aged individuals in the Malmö offspring study
}

Per Swärd ${ }^{1 *+}$ (D), Rafid Tofik ${ }^{2+}$, Omran Bakoush ${ }^{3,4}$, Ole Torffvit ${ }^{5}$, Peter M. Nilsson ${ }^{6}$ and Anders Christensson ${ }^{7}$

\begin{abstract}
Background: Increased urinary excretion of lgM and low-grade albuminuria are associated with increased risk of cardiovascular morbidity and mortality. The objective of this study was to investigate the association between urinary lgM, albuminuria, and vascular parameters reflecting arterial structure and function.

Methods: Subjects of the present study were from the Malmö Offspring study (MOS) cohort, and included 1531 offspring (children and grand-children) to first-generation subjects that participated in the Malmö Diet CancerCardiovascular Arm study cohort. At baseline, technical measurements of arterial stiffness (carotid-femoral pulse wave velocity; c-f PWV), carotid arterial morphology, 24-h ambulatory blood pressure recordings, ankle-brachialindex $(A B I)$, and evaluation of endothelial function (reactive hyperemia index, RHI) were performed. Urinary $(U) \lg M$, $\mathrm{U}$-albumin, and U-creatinine were measured. Multivariate adjusted logistic regression was used to test whether UIgM excretion and increasing urinary albumin excretion were related to vascular parameters.

Results: Detectable U-IgM was independently associated with higher systolic blood pressure, odds ratio (OR) $1.021,95 \%$ confidence interval $(C l, 1.003-1.039), p=0.025$ and lower $A B I ; A B I d x: O R 0.026,95 \% \mathrm{Cl}(0.002-$ $0.381), p=0.008, \mathrm{ABI}$ sin: $\mathrm{OR} 0.040,95 \% \mathrm{Cl}(0.003-0.496), p=0.012$. Low-grade albuminuria was independently associated with systolic and diastolic blood pressure, aortic blood pressure, the c-f PWV and the number of carotid intima plaques $(p<0.05)$.

Conclusions: In young to middle-aged, mostly healthy individuals, increased U-IgM excretion and low-grade albuminuria are associated with adverse vascular parameters. Increased U-IgM excretion may reflect subclinical peripheral atherosclerosis, whereas increased $\mathrm{U}$-albumin excretion is associated with a wide range of cardiovascular abnormalities. This may reflect different pathophysiological mechanisms.
\end{abstract}

Keywords: Ankle-brachial-index, Arteriosclerosis, Albumin creatinine ratio, Atherosclerosis, Glomerular filtration barrier, Pulse wave velocity, Microalbuminuria, Urinary lgM

\footnotetext{
* Correspondence: per.sward@skane.se

'Per Swärd and Rafid Tofik contributed equally to this work.

'Department of Orthopedics, Clinical Sciences, Clinical and Molecular

Osteoporosis Research Unit, Lund University, Skåne University Hospital, 205

02 Malmö, SE, Sweden

Full list of author information is available at the end of the article
}

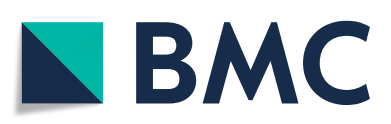

(c) The Author(s). 2020 Open Access This article is licensed under a Creative Commons Attribution 4.0 International License, which permits use, sharing, adaptation, distribution and reproduction in any medium or format, as long as you give appropriate credit to the original author(s) and the source, provide a link to the Creative Commons licence, and indicate if changes were made. The images or other third party material in this article are included in the article's Creative Commons licence, unless indicated otherwise in a credit line to the material. If material is not included in the article's Creative Commons licence and your intended use is not permitted by statutory regulation or exceeds the permitted use, you will need to obtain permission directly from the copyright holder. To view a copy of this licence, visit http://creativecommons.org/licenses/by/4.0/ The Creative Commons Public Domain Dedication waiver (http://creativecommons.org/publicdomain/zero/1.0/) applies to the data made available in this article, unless otherwise stated in a credit line to the data. 


\section{Background}

Several biomarkers have been shown to be prognostic of cardiovascular risk, but most do not improve clinical prediction when combined with traditional risk factors; age, sex, hypertension, diabetes, blood lipids and smoking. Some of the most prominent markers of cardiovascular risk which have also been shown to independently predict cardiovascular events, include impaired kidney function $[1,2]$, large artery stiffening [3-5], the ankle-brachial index, ABI (a marker of peripheral atherosclerosis) [6-8], as well as markers of injury to the glomerular filtration barrier (GFB) [9-11].

Low grade albuminuria/microalbuminuria $(3-30 \mathrm{mg}$ albumin/mmol creatinine or $30-300 \mathrm{mg}$ albumin/g creatinine), or 20 to $200 \mu \mathrm{g}$ albumin excreted in the urine per minute (daytime)) is well-known to predict cardiovascular events and mortality in various clinical cohorts, but also in subjects with hypertension and diabetes from the general population [12]. These findings are independent of renal function (estimated glomerular filtration rate; eGFR), and are believed to represent a link between albuminuria, atherosclerosis and systemic endothelial dysfunction $[11,13,14]$.

In middle-aged and elderly individuals, levels of urinary albumin excretion $>6.8 \mu \mathrm{g}$ albumin excreted in the urine per minute (daytime) was associated with cardiovascular morbidity and mortality in the general population [13]. Abnormal atherosclerotic conditions, i.e. arterial stiffness, carotid plaques and peripheral artery disease, was more common at a U-albumin/creatinine ratio (U-ACR) $>15$ $\mathrm{mg} / \mathrm{g}$ ( equivalent to $1,5 \mathrm{mg}$ albumin $/ \mathrm{mmol}$ creatinine) [15]. However, the association between normoalbuminuria/ microalbuminuria and abnormal cardiovascular conditions such as arterial stiffness, manifest atherosclerosis and markers of endothelial dysfunction in younger populations is not well documented.

We have previously shown in clinical studies that increased urinary excretion of IgM is independently associated with increased risk of subsequent cardiovascular events and mortality in subjects with diabetes (type 1 and 2) $[10,16]$. The same was true in patients with acute coronary syndrome (ACS) and in subjects presenting to the emergency room with acute chest pain, without ACS $[9,17]$. Interestingly, the highest risk of cardiovascular events or mortality was observed in subjects who had a combination of increased urinary IgM excretion and low grade albuminuria $[9,10,16]$. Normally, because of its size, IgM (120 $)$ does not pass the GFB, unless there are large defects in the GFB ("shunts") [18-20]. The prevalence of increased urinary IgM excretion in the general population is unknown. Nor has it been investigated whether urinary IgM excretion is associated with abnormal cardiovascular conditions reflecting vascular ageing [21], such as arterial stiffness, manifest atherosclerosis or markers of endothelial dysfunction.
Therefore, the aim of the present observational study was to investigate the association between albuminuria and urinary IgM with adverse vascular parameters, including blood pressure, carotid intima plaques, carotidfemoral pulse wave velocity (c-f PWV), ankle-brachial index (ABI), and reactive hyperemia index (RHI) in an urban population. Furthermore, we assessed kidney function which could affect the association between albuminuria, urinary IgM and vascular parameters.

\section{Methods}

Included in the present study were 1531 subjects from the Malmö Offspring study (MOS), children and grandchildren, i.e. offspring, to first-generation subjects that participated in the Malmö Diet Cancer-Cardiovascular Arm (MDC-CV) study cohort at baseline [22], after identification based on official register information. Subjects were invited to a clinical and technical examination at the Clinical Research Unit (CRU), Skåne University Hospital, Malmö, during 2013 to 2017. The following baseline investigations were obtained in both children and grand-children (generations 2 and 3); age (y), height $(\mathrm{m})$, weight $(\mathrm{kg}),(\mathrm{cm})$ and BMI $\left(\mathrm{kg} / \mathrm{m}^{2}\right)$, waist circumference $(\mathrm{cm})$, blood pressure $(\mathrm{mmHg}), \mathrm{ABI}$ and questionnaire data. The participants' height $(\mathrm{m})$ was measured to the nearest centimeter with the participant looking straight ahead, the legs together, and wearing indoor clothing without shoes or hats. Weight $(\mathrm{kg})$ was measured using a calibrated balance beam or digital scale. Waist circumference $(\mathrm{cm})$ was measured midway between the lowest rib margin and iliac crest. Blood pressure $(\mathrm{mmHg})$ was measured after $10 \mathrm{~min}$ of rest lying down and the ABI was calculated. At the study start subjects answered detailed questions on family, medical, social and educational history by a web-based questionnaire. Information regarding smoking habits, use of antidiabetic medications, and antihypertensive treatment, was obtained from the questionnaire [23, 24]. Anti-hypertensive treatment included, thiazides, Beta blockers, renin-angiotensin-aldosterone system (RAAS) blockers and calcium antagonists, and in the study sample, $n=70(4.6 \%)$ were treated with one or several antihypertensive drugs. Smokers were categorized as: nonsmokers, current smokers or previous smokers. In Table 1, we present percentages based on the whole cohort. Subjects who did not answer the questionnaire were considered to have responded negatively, adopting a conservative approach. U-albumin/creatinine ratio (UACR) was measured in 1530 (99.9\%), and U-IgM was measured in 1339 (87.5\%) of these subjects.

The ABI was measured using a sphygmomanometer and Doppler device (Hadeco Bidop ES-100 V3) [25]. The systolic blood pressure was measured first in the right arm, then in the right ankle, the left ankle and in the left 


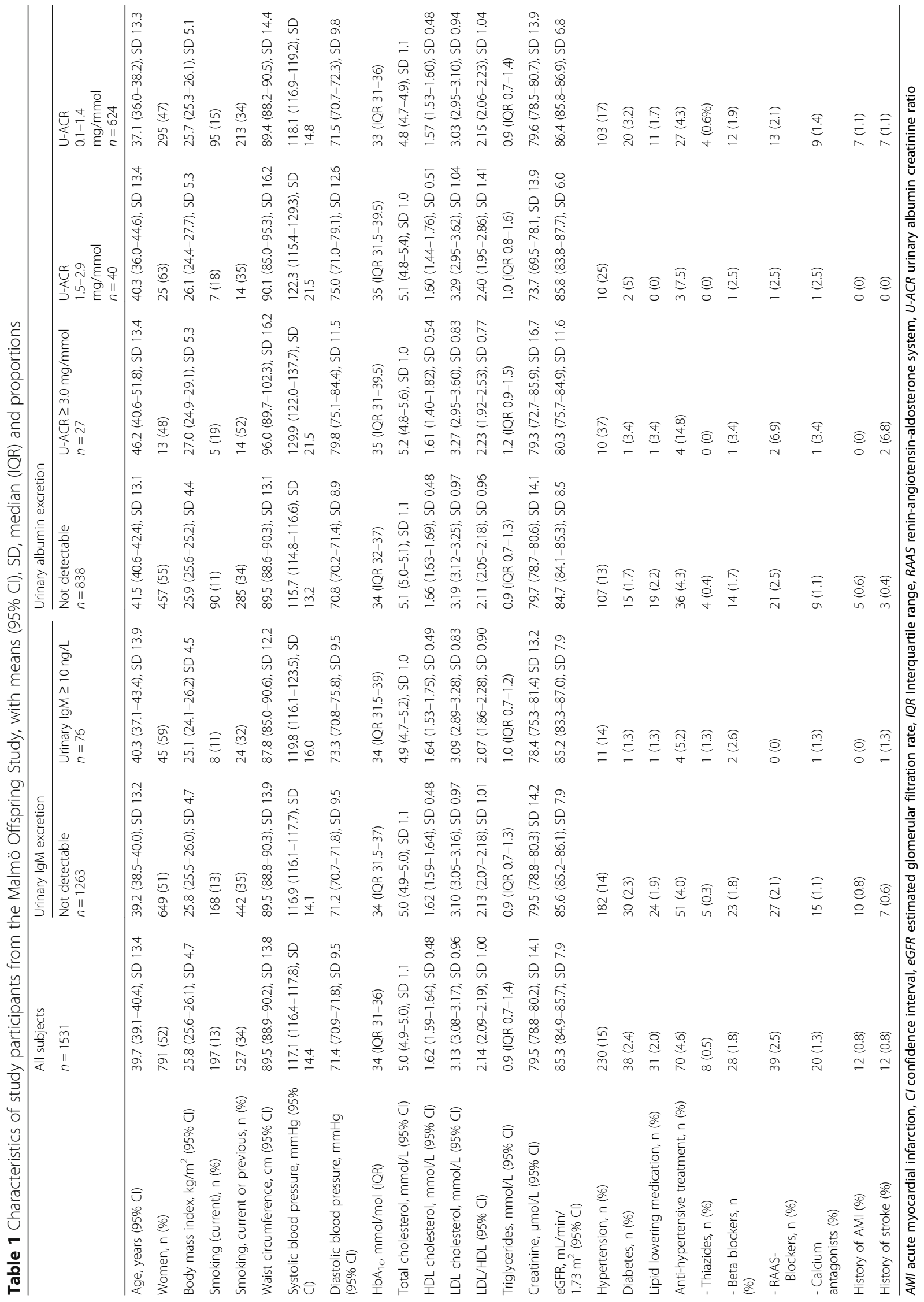


arm. In the ankle, the pressure was measured in both arteria dorsalis pedis and in arteria tibialis posterior, and the left and right ABI was calculated by dividing the highest blood pressure in left and right ankle with the blood pressure from the arm with the highest value. Ambulatory blood pressure $(24 \mathrm{~h})$ and technical measurements of arterial stiffness were performed using TensioMed Arteriograph 24 (TensioMed $^{\text {Tw }}$ Ltd., Hungary). Blood pressure was measured every $15 \mathrm{~min}$ during daytime (06.00-22.00) and every $30 \mathrm{~min}$ during night (22.00-06.00). Brachial systolic and diastolic blood pressure, aortic systolic and diastolic blood pressure, aortic c-f PWV (indirectly) and heart rate were recorded at each measurement. Subjects were excluded from analyses if more than $30 \%$ of the blood pressure recordings were missing $[26,27]$. Aortic c-f PWV was measured only in children (generation 2) using applanation tonometry (SphygmoCor; AtCor Medical, West Ryde, New South Wales, Australia) as described previously [28]. 24$\mathrm{h}$ blood pressure measurements were made in a random sample of the cohort. Measurements of carotid artery morphology were also performed only in children (generation 2) and performed as described previously using ultrasound examinations with Acuson Sequoia 512 (Acuson, Mountain View, CA, USA). A $7 \mathrm{MHz}$ linear array transducer was used, and images of all plaques within the left right carotid artery were obtained, using fixed machine settings by experienced sonographers. A plaque was defined as a focal thickening of intimamedia greater than $1.2 \mathrm{~mm}$ when measured from the media-adventitia interface to the intima-lumen interface [29], and subjects were considered to have a maximum of three plaques (common carotid artery, internal carotid artery and the carotid bifurcation). Evaluation of endothelial function by calculation of the reactive hyperemia index (RHI, EndoPAT; Itamar Medical Ltd, Cesarea, Israel) in a finger were made in a random sample of all included subjects, as described previously [30].

\section{Laboratory methods}

Blood samples and urine were collected after an overnight fast. Plasma- creatinine levels were determined by an enzymatic colorimetric assay using a calibrator traceable to primary reference material with values assigned by isotope dilution mass spectrometry (IDMS) [31]. Cystatin C levels were determined by a particleenhanced immunoturbidimetric method using a reference material traceable to the international cystatin $\mathrm{C}$ calibrator [32, 33]. Standard procedures were used to measure $\mathrm{HbA}_{1 \mathrm{c}}$, total cholesterol and HDL cholesterol at the Department of Clinical Chemistry, Skåne University Hospital, Malmö, Sweden. The Friedwald's formula was used to calculate LDL cholesterol [34]. Estimated glomerular filtration rate (eGFR) was calculated using both creatinine and cystatin $\mathrm{C}$ and a mean of these two was created [32, 35]. Urine creatinine and albumin were measured on fresh urine samples taken at study start using standard procedures at the Department of Clinical Chemistry, Skåne University Hospital. Urine albumin concentration was measured by immunoturbidometry and the urine albumin/creatinine ratio (ACR) was calculated. All urine samples were stored at $-80^{\circ} \mathrm{C}$ at the Region Skåne Biobank (BD47) before measurement of urine IgM, and the urine $\operatorname{IgM} /$ creatinine ratio was calculated. Urinary albumin excretion was defined as microalbuminuria (ACR $>2.9 \mathrm{mg} / \mathrm{mmol}$ ) and high or low normoalbuminuria, using a cut-off at ACR $1.5 \mathrm{mg} / \mathrm{mmol}$, based on findings from Lee et al. [15]. U-IgM was measured with an in-house ELISA method, described in detail elsewhere [36]. The lower detection limit for the U-IgM assay is $10 \mathrm{ng} / \mathrm{l}$. The proportion of subjects that have undergone the various examinations performed in the present study is shown in Supplementary Table 1.

\section{Statistical methods}

Data is presented as mean and 95\% confidence intervals $(\mathrm{CI})$, median and interquartile range or numbers and percentages as appropriate. We used multivariable adjusted logistic regression to test whether U-IgM excretion (detectable compared with non-detectable urine IgM) and increasing urinary albumin excretion (U-ACR $>2.9$, U-ACR $1.5-2.9$ and U-ACR $0.1-1.4 \mathrm{mg} / \mathrm{mmol}$ compared with non-detectable urine albumin) were related to vascular parameters. In a multivariable logistic regression model, we adjusted for predefined variables; age, sex, BMI, eGFR, current smoker (risk factors for CV disease) and antihypertensive treatment (hypertension is a risk factor for $\mathrm{CV}$ disease and antihypertensive drugs may affect glomerular filtration of albumin, and IgM). Smoking status was known from the web-based questionnaire in 1323/1531 (86.4\%) subjects. In the multivariable logistic regression model, subjects who did not answer the questionnaire were treated as non-smokers, adopting a conservative approach. To test if detectable urinary IgM was associated with increasing levels of urinary albumin excretion (non-detectable urine albumin, low normoalbuminuria, high normoalbuminuria, or microalbuminuria), a multivariable logistic regression model was used, adjusted for age and sex. Reported $p$ values are 2 -tailed and the level of significance was set at $p<0.05$. All analyses were performed in the SPSS statistical package (v24; SPSS Inc., Chicago, Ill).

\section{Results}

\section{Participant baseline characteristics}

In this sub-study from MOS, 1531 subjects where included and the age of the study population was mean 39 years (95\% CI 39-40y, SD 13y, range 18-69y). Among 
these, 740 were men (48\%) and 791 women (52\%). There were 197 (12.9\%) current smokers and 329 (21.5\%) previous smokers in the whole cohort. The mean body mass index (BMI) was $25.8 \mathrm{~kg} / \mathrm{m}^{2}$ (95\% CI: 25.6-26.1; SD 4.7). Thirty-eight (2.4\%) subjects had diabetes mellitus, 70 (4.6\%) were on anti-hypertensive treatment and 31 (2.0\%) had lipid-lowering treatment. Twelve $(0.8 \%)$ subjects had history of acute myocardial infarction (AMI) and $12(0.8 \%)$ had history of stroke at baseline. In 838 $(54.7 \%)$ of subjects, urinary albumin could not be detected, 624 (40.8\%) had U-ACR levels between 0.1 and $1.4 \mathrm{mg} / \mathrm{mmol}, 40(2.6 \%)$ between 1.5 and 2.9 , and 27 (1.8\%) had U-ACR levels $\geq 3.0$. In 76 of 1339 (5.7\%) subjects, IgM was detected in urine and the median urinary $\mathrm{IgM} / \mathrm{creatinine}$ ratio was $1.56 \mu \mathrm{g} / \mathrm{mol}$, with the 25 th75th percentile ranging from $0.90-2.57 \mu \mathrm{g} / \mathrm{mol})$. Urinary IgM was not detected in 1263 of 1339 (94.3\%) subjects. Baseline characteristics based on detectable IgM or not, as well as non-detectable urine albumin, low- or high normoalbuminuria and microalbuminuria, are shown in Table 1.

Based on means and 95\% CI, medians and IQR, numbers and percentages, there were no apparent associations between self-reported diabetes, previous cardiovascular events or eGFR and normoalbuminuria, microalbuminuria or detectable urine IgM in the cohort (Table 1). However, age and the proportion of subjects with self-reported smoking, hypertension and antihypertensive treatment, and the mean systolic and diastolic blood pressures, were higher among subjects with microalbuminuria compared to subjects with non-detectable urine albumin (Table 1). The proportion of subjects with antihypertensive treatment was also slightly higher among subjects with IgMuria and those with high grade normoalbuminuria compared to subjects without detectable urine IgM and albumin, respectively.

Detectable urinary IgM was associated with increasing levels of urinary albumin excretion, OR 1.4 (95\% confidence interval 1.1-1.8, $p=0.002$ ).

\section{Vascular markers and endothelial function in relation to urinary albumin- and IgM-excretion}

In a multivariable logistic regression model where adjustment was made for predefined variables: age, sex, BMI, eGFR and current smoker, detectable urine IgM was significantly associated with higher systolic blood pressure and lower ABI in both models. Further adjustment for systolic blood pressure did not change the results (data not shown). Microalbuminuria and high normoalbuminuria were in the same models associated with systolic and diastolic blood pressure of the brachial artery and systolic blood pressure of the aorta, as well as the aortic c-f PWV and the number of carotid intima plaques. Neither urinary
IgM excretion or microalbuminuria, nor high or low normoalbuminuria was associated with the RHI (Table 2).

\section{Discussion}

The main finding of the present observational study involving young to middle-aged and mostly healthy individuals was that detectable urinary IgM (U-IgM) was associated with lower ankle brachial index (ABI). There was also a weak association between U-IgM and higher systolic blood pressure, however, this association was not observed between U-IgM and 24-h mean systolic blood pressure. Other markers of hypertension, arterial stiffness and endothelial dysfunction, did not associate with U-IgM in the present study. On the other hand, high-grade normoalbuminuria (ACR 1.5-2.9) and microalbuminuria (ACR $\geq 3.0 \mathrm{mmol} / \mathrm{mg}$ ) were associated with clinical markers of hypertension, arterial stiffness and carotid atherosclerosis, but not RHI (marker of endothelial dysfunction) nor ABI (marker of peripheral atherosclerosis). Low-grade normoalbuminuria (ACR $0.1-1.4 \mathrm{mg} /$ $\mathrm{mmol}$ ) was associated with higher systolic and diastolic blood pressure. Based on these findings it could be speculated that microalbuminuria and a high normal range of albuminuria of $>1.5 \mathrm{mg} / \mathrm{mmol}$ reflects both arteriosclerosis (vascular function), i.e. morphological characteristics of the tunica media of large elastic arteries involving decreased elastin and higher collagen content [3], and subclinical atherosclerosis (vascular structure), which is associated with narrowing of the arterial lumen secondary to accumulating cells and lipids in the tunica intima [37]. Speculatively, U-IgM may therefore more specifically reflect subclinical peripheral atherosclerosis than arteriosclerosis. Nevertheless, we also found that detectable U-IgM was associated with increasing levels of urinary albumin excretion, suggesting that the pathogenesis underlying increased U-IgM and urinary albumin excretion are partly overlapping.

These results strengthen previous findings suggesting different pathogenesis leading to increased urinary albumin and IgM excretion, respectively. High levels of UIgM excretion, independently of low grade albuminuria, was associated with increased cardiovascular events and mortality in patients with type 1 and 2 diabetes, but also in patients with acute chest pain $[9,10,16]$. Furthermore, low grade albuminuria to a greater extent reflected systemic inflammation [38], and the strongest predictive value predicting future cardiovascular risk was found when combining low grade albuminuria and U$\operatorname{IgM}[9,10,38]$.

With reference to the two-pore theory of glomerular permeability, only a very small amount of albumin (radius $35.5 \AA$ ) passes the glomerular filtration barrier (GFB; 1 of 10,000 albumin molecules). Larger proteins, including IgM (radius $120 \AA$ ), pass the GFB at much 


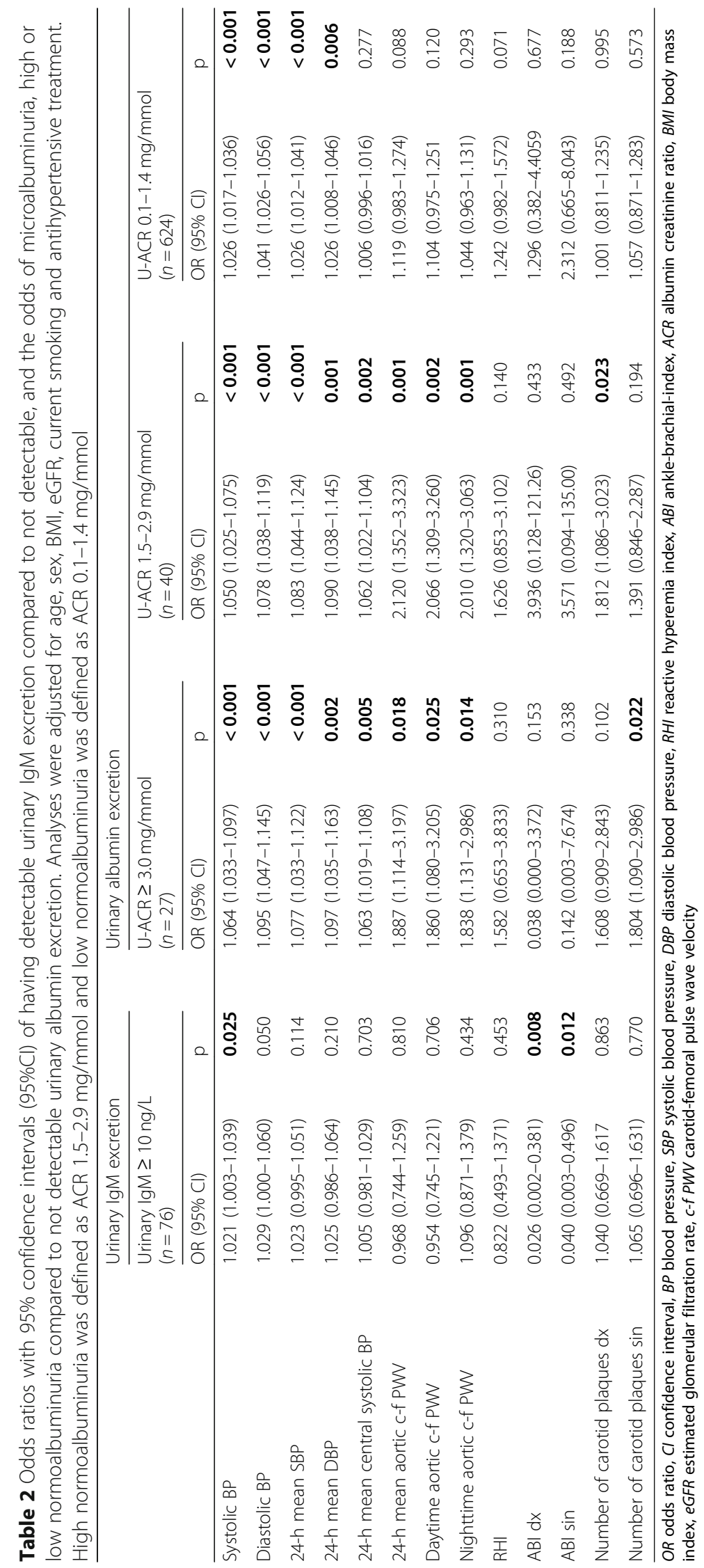


lower rates, and only through large defects (shunts), indicative of severe injury to the GFB [18-20].

In the present study, $6 \%$ of the study participants had detectable concentrations of U-IgM, which could suggest that these individuals are afflicted by some degree of structural injury to the GFB. These findings were unrelated to age, sex, eGFR, previous $\mathrm{CV}$ events, diabetes and drugs to treat hypertension or hyperlipidemia. However, the presence of urinary IgM was associated with a higher systolic blood pressure and a lower ABI. The latter is a well-known marker of peripheral artery disease and associated with generalized atherosclerosis, CV events and mortality [6-8]. Therefore, it is plausible that the observed relation between urinary IgM and $A B I$ is related to subclinical atherosclerosis leading to elevated glomerular vascular resistance, glomerular ischemia, and remodeling of the GFB with an increased number of non-selective glomerular shunt-pathways [19, 39-41].

Furthermore, $2 \%$ of participants had microalbuminuria, 3\% had high-grade normoalbuminuria and $41 \%$ had low-grade normoalbuminuria. Microalbuminuria is associated with systemic inflammation, endothelial dysfunction. It is a well-known risk marker for atherosclerosis, artery stiffness, cardiovascular morbidity and mortality in subjects with diabetes and in populations with increased cardiovascular risk [12, 13, 42, 43]. Later it was shown that these findings also apply to subjects without hypertension or diabetes in middle-aged and elderly individuals. Here we show similar findings in a younger population of mostly healthy individuals. Our findings are in line with several studies which suggest that a U-ACR cutoff below $3 \mathrm{mg} / \mathrm{mmol}$ should be used when considered as a risk marker of cardiovascular risk in non-diabetic subjects $[11,13,15,44]$. We did, however, not find an association between low grade albuminuria and RHI measured in the finger, a marker of endothelial dysfunction, which has been found in other studies of subjects with type 2 diabetes [45]. This could be related to the fact that our study population is younger and mostly healthy, or that the present study was underpowered to detect these differences.

The pathophysiological mechanism linked to increased albumin excretion are multifactorial and mediated by increased renal vascular resistance secondary to atherosclerosis, arteriosclerosis and hypertension, chronic inflammation, increased RAAS activity and dysfunction of other hormonal systems [46-49]. Hence, increased urinary albumin excretion as a marker of permanent glomerular/endothelial dysfunction and increased cardiovascular risk has some limitations because it varies depending on systemic inflammatory and hormonal status $[46,47,49]$. This study extends previous investigations by showing associations between the level of urinary albumin excretion and hypertension as well as markers of arterial stiffness and subclinical atherosclerosis in young and mostly healthy individuals. Therefore, microalbuminuria and high normoalbuminuria could be predictive of subsequent cardiovascular morbidity also in younger mostly healthy individuals, to be further explored in our cohort. The different molecular sizes of albumin (molecular radius $35.5 \AA$ ) and IgM (molecular radius $120 \AA$ ) explains differences in excretion since elimination of IgM through the GFB requires a more extensive barrier damage compared to albumin. This may explain differences in the effect on the evaluated atherosclerotic vascular parameters in this study. The presence of IgM in the urine could demonstrate another or more severe damage of the GFB. Therefore, further evaluation of this phenomenon may lead to a better understanding of the significance of the urinary filtration quality. However, quantification of proteinuria is complicated due to reabsorption in the tubular part. Overloading of the reabsorption capacity leads to measurable proteinuria. Reabsorption capacity of albumin and IgM may differ and jeopardize the interpretation.

There are some strengths and limitations of our study to be acknowledged. The community-based study population of the present study has been well characterized which is an important strength. In this study population of younger, mostly healthy individuals there was only a small percentage of subjects with low grade albuminuria (2\%) and detectable U-IgM (6\%). This limits our study by precluding more extensive multivariable analyses, why we decided to only include age, sex, BMI, eGFR, smoking and anti-hypertensive treatment in the multivariable analyses. To various degree the subjects had not underwent all technical examinations used in MOS, and $15 \%$ had not filled the questionnaires which is a limitation of the study. Also, the detection limit of our U-IgM assay, in combination with the level of concentration of IgM in the primary urine, influences which subject for whom we can detect IgM in the urine. This must be considered a weakness. Another weakness of the study is that information about pharmacological treatment and medical history was gained from a self-administered questionnaire. Also, U-IgM may not only be related to the glomerular permeability, but also to the degree of tubular reabsorption/excretion and discharge from the bladder, urethra etc.

\section{Conclusions}

When measured in younger, mostly healthy individuals, increased urinary IgM excretion and low-grade albuminuria are associated with vascular parameters reflecting vascular ageing and increased risk of cardiovascular morbidity and mortality. This study suggests that increased urinary IgM may be a more specific marker of atherosclerosis (associates with $\mathrm{ABI}$ ), whereas increased 
albumin excretion could be mediated or reflected by a wide variety of cardiovascular abnormalities. By measuring both urinary albumin and IgM excretion (in combination with other known risk factors), the prognostic ability to estimate the overall cardiovascular risk could be increased and also reflect different targets of the examined vascular parameters. This needs to be addressed in future prospective investigations.

\section{Supplementary information}

Supplementary information accompanies this paper at https://doi.org/10 1186/s12872-020-01638-3.

Additional file 1: Supplementary Table 1. The proportion of subjects that have undergone the various examinations performed in the present study

\section{Abbreviations \\ Cl: Confidence interval; AMI: Acute myocardial infarction; IQR: Interquartile range; RAAS: Renin-angiotensin-aldosterone system; eGFR: Estimated glomerular filtration rate; $\mathrm{ABI}$ : Ankle-brachial-index; ACR: Albumin creatinine ratio; BMI: Body mass index; c-f PWV: Carotid-femoral pulse wave velocity; RHI: Reactive hyperemia index; MOS: Malmö offspring study; U: Urine; GFB: Glomerular filtration barrier; CV: Cardiovascular}

\section{Acknowledgements}

We acknowledge the skillful technical assistance by Åsa Pettersson for laboratory analyses.

\section{Authors' contributions}

The present sub study on the MOS cohort for which PN is principal investigator was designed by PS, RT, PN and AC. Data were analyzed by PS, RT, OB, OT, PN and AC. PS wrote the first draft of the manuscript. All authors critically assessed the manuscript and approved the final manuscript.

\section{Funding}

This study was in part supported the Research Council of Sweden and the Heart- and Lung Foundation (grants to PN), but also by the Region Skane County Council (ALF grants to PN and PS). None of the funders had any influence on study design, data collection, interpretation or writing of the manuscript. Open access funding provided by Lund University.

\section{Availability of data and materials}

All data generated or analyzed during this study are included in this published article. Corresponding author (PS) can be contacted for more information.

\section{Ethics approval and consent to participate}

Ethical approval has been obtained for MOS at the Regional Ethics Committee at the Lund University, Lund, Sweden (Dnr. 2012/594). All patients provided written informed consent.

\section{Consent for publication}

Not applicable.

\section{Competing interests}

None of the authors has any disclosures or competing interests.

\section{Author details}

${ }^{1}$ Department of Orthopedics, Clinical Sciences, Clinical and Molecular Osteoporosis Research Unit, Lund University, Skåne University Hospital, 205 02 Malmö, SE, Sweden. ${ }^{2}$ Department of Emergency medicine, Clinical Sciences, Lund University, Skåne University Hospital, Malmö, Sweden. ${ }^{3}$ Department of Nephrology, Clinical Sciences, Lund University, Skåne University Hospital, Lund, Sweden. ${ }^{4}$ Department of Internal Medicine, College of Medicine and Health sciences, UAEU, Al Ain, United Arab Emirates. ${ }^{5}$ Department of Nephrology, Clinical Sciences, Lund University, Skåne
University Hospital, Lund, Sweden. ${ }^{6}$ Department of Clinical Sciences and Internal Medicine, Lund University Skane University Hospital, Malmo, Sweden. ${ }^{7}$ Department of Nephrology, Clinical Sciences, Lund University, Skåne University Hospital, Malmö, Sweden.

Received: 17 April 2020 Accepted: 22 July 2020

Published online: 05 August 2020

\section{References}

1. Go AS, Chertow GM, Fan D, McCulloch CE, Hsu CY. Chronic kidney disease and the risks of death, cardiovascular events, and hospitalization. N Engl J Med. 2004;351(13):1296-305.

2. Weiner DE, Tighiouart H, Amin MG, Stark PC, MacLeod B, Griffith JL, et al. Chronic kidney disease as a risk factor for cardiovascular disease and allcause mortality: a pooled analysis of community-based studies. J Am Soc Nephrol. 2004;15(5):1307-15.

3. Bonarjee WS. Arterial stiffness: a prognostic marker in coronary heart disease. Available Methods and Clinical Application. Front Cardiovasc Med. 2018;5:64.

4. Laurent S, Boutouyrie P, Asmar R, Gautier I, Laloux B, Guize L, et al. Aortic stiffness is an independent predictor of all-cause and cardiovascular mortality in hypertensive patients. Hypertension. 2001;37(5):1236-41.

5. Verbeke F, Van Biesen W, Honkanen E, Wikstrom B, Jensen PB, Krzesinski JM et al. Prognostic value of aortic stiffness and calcification for cardiovascular events and mortality in dialysis patients: outcome of the calcification outcome in renal disease (CORD) study. Clin J Am Soc Nephrol. 2011:6(1): 153-9.

6. Ankle Brachial Index C, Fowkes FG, Murray GD, Butcher I, Heald CL, Lee R, et al. Ankle brachial index combined with Framingham Risk Score to predict cardiovascular events and mortality: a meta-analysis. JAMA. 2008;300(2):197-208.

7. Fowkes FG, Murray GD, Butcher I, Folsom AR, Hirsch AT, Couper DJ, et al. Development and validation of an ankle brachial index risk model for the prediction of cardiovascular events. Eur J Prev Cardiol. 2014:21(3):310-20.

8. American College of Cardiology F, American Heart Association task F, Society for Cardiovascular a, interventions, Society of Interventional R, Society for Vascular M, Society for Vascular S, et al. 2011 ACCF/AHA focused update of the guideline for the management of patients with peripheral artery disease (updating the 2005 guideline). Vasc Med. 2011;16(6):452-76.

9. Tofik R, Sward P, Ekelund U, Struglics A, Torffvit O, Rippe B, et al. Plasma pro-inflammatory cytokines, IgM-uria and cardiovascular events in patients with chest pain: a comparative study. Scand J Clin Lab Invest. 2015;75(8): 638-45.

10. Tofik R, Torffvit O, Rippe B, Bakoush O. Increased urine IgM excretion predicts cardiovascular events in patients with type 1 diabetes nephropathy BMC Med. 2009;7:39

11. Arnlov J, Evans JC, Meigs JB, Wang TJ, Fox CS, Levy D, et al. Low-grade albuminuria and incidence of cardiovascular disease events in nonhypertensive and nondiabetic individuals: the Framingham heart study. Circulation. 2005;112(7):969-75

12. Gerstein HC, Mann JF, Yi Q, Zinman B, Dinneen SF, Hoogwerf B, et al. Albuminuria and risk of cardiovascular events, death, and heart failure in diabetic and nondiabetic individuals. JAMA. 2001;286(4):421-6.

13. Klausen K, Borch-Johnsen K, Feldt-Rasmussen B, Jensen G, Clausen P, Scharling $\mathrm{H}$, et al. Very low levels of microalbuminuria are associated with increased risk of coronary heart disease and death independently of renal function, hypertension, and diabetes. Circulation. 2004;110(1):32-5.

14. Reinhard H, Wiinberg N, Hansen PR, Kjaer A, Petersen CL, Winther $K$, et al. NT-proBNP levels, atherosclerosis and vascular function in asymptomatic type 2 diabetic patients with microalbuminuria: peripheral reactive hyperaemia index but not NT-proBNP is an independent predictor of coronary atherosclerosis. Cardiovasc Diabetol. 2011;10:71.

15. Lee YH, Kweon SS, Choi JS, Rhee JA, Nam HS, Jeong SK, et al. Determining the optimal cut-off value of the urinary albumin-to-creatinine ratio to detect atherosclerotic vascular diseases. Kidney Blood Press Res. 2012;36(1):290-300.

16. Tofik $\mathrm{R}$, Torffvit $\mathrm{O}$, Rippe $\mathrm{B}$, Bakoush $\mathrm{O}$. Urine IgM-excretion as a prognostic marker for progression of type 2 diabetic nephropathy. Diabetes Res Clin Pract. 2012:95(1):139-44.

17. Tofik R, Ekelund U, Torffvit O, Sward P, Rippe B, Bakoush O. Increased urinary IgM excretion in patients with chest pain due to coronary artery disease. BMC Cardiovasc Disord. 2013;13:72. 
18. Tencer J, Frick IM, Oquist BW, Alm P, Rippe B. Size-selectivity of the glomerular barrier to high molecular weight proteins: upper size limitations of shunt pathways. Kidney Int. 1998;53(3):709-15.

19. Bakoush O, Segelmark M, Torffvit O, Ohlsson S, Tencer J. Urine IgM excretion predicts outcome in ANCA-associated renal vasculitis. Nephrol Dial Transplant. 2006;21(5):1263-9.

20. Haraldsson B, Nystrom J, Deen WM. Properties of the glomerular barrier and mechanisms of proteinuria. Physiol Rev. 2008;88(2):451-87.

21. Nilsson PM, Boutouyrie P, Cunha P, Kotsis V, Narkiewicz K, Parati G, et al. Early vascular ageing in translation: from laboratory investigations to clinical applications in cardiovascular prevention. J Hypertens. 2013; 31(8):1517-26.

22. Hedblad B, Nilsson P, Janzon L, Berglund G. Relation between insulin resistance and carotid intima-media thickness and stenosis in non-diabetic subjects. Results from a cross-sectional study in Malmo, Sweden. Diabet Med. 2000;17(4):299-307.

23. Ottosson F, Brunkwall L, Ericson U, Nilsson PM, Almgren P, Fernandez C, et al. Connection between BMI-related plasma metabolite profile and gut microbiota. J Clin Endocrinol Metab. 2018;103(4):1491-501.

24. Jonsson D, Orho-Melander M, Demmer RT, Engstrom G, Melander O, Klinge $B$, et al. Periodontal disease is associated with carotid plaque area: the Malmo offspring dental study (MODS). J Intern Med 2020;287(3):301-9.

25. Chahal S, Vohra K, Syngle A. Association of sudomotor function with peripheral artery disease in type 2 diabetes. Neurol Sci. 2017;38(1):151-6.

26. Fatehali AA, Gottsater M, Nilsson PM. Family history of cardiometabolic diseases and its association with arterial stiffness in the Malmo diet Cancer cohort. J Hypertens. 2017;35(11):2262-7.

27. Gottsater M, Hindy G, Orho-Melander M, Nilsson PM, Melander O. A genetic risk score for fasting plasma glucose is independently associated with arterial stiffness: a Mendelian randomization study. J Hypertens. 2018;36(4): 809-14.

28. Muhammad IF, Borne Y, Ostling G, Kennback C, Gottsater M, Persson M, et al. Arterial stiffness and incidence of diabetes: a population-based cohort study. Diabetes Care. 2017:40(12):1739-45.

29. Rosvall M, Janzon L, Berglund G, Engstrom G, Hedblad B. Incident coronary events and case fatality in relation to common carotid intima-media thickness. J Intern Med. 2005;257(5):430-7.

30. Bassareo PP, Fanos V, Puddu M, Demuru P, Cadeddu F, Balzarini M, et al. Reduced brachial flow-mediated vasodilation in young adult ex extremely low birth weight preterm: a condition predictive of increased cardiovascular risk? J Matern Fetal Neonatal Med. 2010;23(Suppl 3):121-4.

31. Bjork J, Grubb A, Larsson A, Hansson LO, Flodin M, Sterner G, et al. Accuracy of GFR estimating equations combining standardized cystatin $C$ and creatinine assays: a cross-sectional study in Sweden. Clin Chem Lab Med. 2015;53(3):403-14.

32. Grubb A, Horio M, Hansson LO, Bjork J, Nyman U, Flodin M, et al. Generation of a new cystatin C-based estimating equation for glomerular filtration rate by use of 7 assays standardized to the international calibrator. Clin Chem. 2014;60(7):974-86.

33. Kyhse-Andersen J, Schmidt C, Nordin G, Andersson B, Nilsson-Ehle P, Lindstrom $V$, et al. Serum cystatin C, determined by a rapid, automated particle-enhanced turbidimetric method, is a better marker than serum creatinine for glomerular filtration rate. Clin Chem. 1994;40(10):1921-6.

34. Friedewald WT, Levy Rl, Fredrickson DS. Estimation of the concentration of low-density lipoprotein cholesterol in plasma, without use of the preparative ultracentrifuge. Clin Chem. 1972;18(6):499-502.

35. Bjork J, Grubb A, Sterner G, Nyman U. Revised equations for estimating glomerular filtration rate based on the Lund-Malmo study cohort. Scand J Clin Lab Invest. 2011;71(3):232-9.

36. Tencer J, Torffvit O, Thysell H, Rippe B, Grubb A. Proteinuria selectivity index based upon alpha 2-macroglobulin or lgM is superior to the lgG based index in differentiating glomerular diseases. Technical note. Kidney Int. 1998; 54(6):2098-105.

37. Linton MRF, Yancey PG, Davies SS, Jerome WG, Linton EF, Song WL, et al. The Role of Lipids and Lipoproteins in Atherosclerosis. In: Feingold KR, Anawalt B, Boyce A, Chrousos G, Dungan K, Grossman A, Hershman JM, Kaltsas G, Koch C, Kopp P, editors. et al Endotext. South Dartmouth (MA); 2000.

38. Tofik R, Ohlsson S, Bakoush O. Urinary concentration of monocyte chemoattractant protein-1 in idiopathic glomerulonephritis: a long-term follow-up study. PLoS One. 2014;9(1):e87857.
39. Bakoush O, Tencer J, Torffvit O, Tenstad O, Skogvall I, Rippe B. Increased glomerular albumin permeability in old spontaneously hypertensive rats. Nephrol Dial Transplant. 2004;19(7):1724-31.

40. Diamond JR. Analogous pathobiologic mechanisms in glomerulosclerosis and atherosclerosis. Kidney Int Suppl. 1991;31:S29-34.

41. Rippe C, Rippe A, Larsson A, Asgeirsson D, Rippe B. Nature of glomerular capillary permeability changes following acute renal ischemia-reperfusion injury in rats. Am J Physiol Ren Physiol. 2006;291(6):F1362-8.

42. Marshall SM. Natural history and clinical characteristics of CKD in type 1 and type 2 diabetes mellitus. Adv Chronic Kidney Dis. 2014;21(3):267-72.

43. Toyama T, Furuichi K, Ninomiya T, Shimizu M, Hara A, Iwata Y, et al. The impacts of albuminuria and low eGFR on the risk of cardiovascular death, all-cause mortality, and renal events in diabetic patients: meta-analysis. PLoS One. 2013;8(8):e71810.

44. Ratto E, Leoncini G, Viazzi F, Vaccaro V, Parodi A, Falqui $V$, et al. Microalbuminuria and cardiovascular risk assessment in primary hypertension: should threshold levels be revised? Am J Hypertens. 2006; 19(7):728-34 discussion 735-726.

45. Yu Y, Suo L, Yu H, Wang C, Tang H. Insulin resistance and endothelial dysfunction in type 2 diabetes patients with or without microalbuminuria. Diabetes Res Clin Pract. 2004;65(2):95-104.

46. Sward P, Rippe B. Acute and sustained actions of hyperglycaemia on endothelial and glomerular barrier permeability. Acta Physiol (Oxford). 2012; 204(3):294-307.

47. Axelsson J, Rippe A, Sverrisson K, Rippe B. Scavengers of reactive oxygen species, paracalcitol, RhoA, and Rac-1 inhibitors and tacrolimus inhibit angiotensin II-induced actions on glomerular permeability. Am J Physiol Ren Physiol. 2013;305(3):F237-43.

48. Axelsson J, Rippe A, Oberg CM, Rippe B. Rapid, dynamic changes in glomerular permeability to macromolecules during systemic angiotensin ॥ (ANG II) infusion in rats. Am J Physiol Ren Physiol. 2012;303(6):F790-9.

49. Enhorning S, Wang TJ, Nilsson PM, Almgren P, Hedblad B, Berglund G, et al. Plasma copeptin and the risk of diabetes mellitus. Circulation. 2010;121(19): 2102-8

\section{Publisher's Note}

Springer Nature remains neutral with regard to jurisdictional claims in published maps and institutional affiliations.

Ready to submit your research? Choose BMC and benefit from:

- fast, convenient online submission

- thorough peer review by experienced researchers in your field

- rapid publication on acceptance

- support for research data, including large and complex data types

- gold Open Access which fosters wider collaboration and increased citations

- maximum visibility for your research: over $100 \mathrm{M}$ website views per year

At BMC, research is always in progress.

Learn more biomedcentral.com/submissions 